\title{
TREATMENT OF ELECTRIC VEHICLE BATTERY WASTE IN CHINA: A REVIEW OF EXISTING POLICIES
}

\author{
Wenbo LI ${ }^{1}$, Muyi YANG ${ }^{2} 3^{*}$, Ruyin $\mathrm{LONG}^{4}$, Kristy MAMARIL ${ }^{5}$, Yuanying CHI \\ ${ }^{1}$ Business School, Jiangsu Normal University, Xuzhou, 221116 Jiangsu, China \\ ${ }^{2}$ The Data Science Institute, University of Technology Sydney, P.O. Box 123, Broadway, NSW 2007, Australia \\ ${ }^{3}$ Data 61, CSIRO, Eveleigh, NSW 2015, Australia \\ ${ }^{4}$ School of Economics and Management, China University of Mining and Technology, \\ Xuzhou, 221116 Jiangsu, China \\ ${ }^{5}$ Faculty of Engineering and IT, University of Technology Sydney, P.O. Box 123, Broadway, NSW 2007, Australia \\ ${ }^{6}$ School of Economics and Management, Beijing University of Technology, 100124 Beijing, China
}

Received 14 July 2020; accepted 18 December 2020

\author{
Highlights \\ Existing policy framework for EV battery waste treatment in China is reviewed. \\ Key elements of the policy framework are outlined. \\ $>$ Some of the key shortcomings of the policy framework are identified. \\ $>$ Practical policy suggestions are made to overcome these shortcomings.
}

\begin{abstract}
This paper reviews existing policies for supporting the treatment of electric vehicle (EV) battery waste in China, and identifies some of their major shortcomings that policy makers may like to consider while making policy decisions. The shortcomings of existing policies identified in this paper include: 1) no clear provisions for historical and orphan batteries; 2) no target for battery collection; 3 ) unclear definition of the scope of authority among various central and local agencies involved in the regulation of waste battery treatment; 4) unclear requirements for data auditing and verification for tracking the entire life cycle of EV batteries; 5) limited consideration of the challenges to ensure stakeholder cooperation; and 6) no explicit specification of the mechanisms for financing waste battery treatment. This paper also makes some practical policy suggestions for overcoming these shortcomings.
\end{abstract}

Keywords: electric vehicles, extended producer responsibility, waste battery treatment, reuse, recycling, policy.

\section{Introduction}

Global energy consumption by transportation has historically been dominated by petroleum-based fuels, particularly diesel and gasoline. While this domination has contributed to the provision of cheap and reliable transport services and consequently to socio-economic prosperity, it has also made the transport sector one of the largest and fastest-growing emitters of greenhouse gases (GHG), and hence the major contributor to global warming - one of the most pressing challenges of our times (Li et al., 2018; Wang \& Ge, 2019). Redressing this challenge has, therefore, become a policy imperative, and a rapid uptake of electric vehicles (EVs) is widely considered as an attractive option for this purpose. The attractiveness of transport electrification is manifested in a rapid deployment of electric vehicles, with the global EV stock increasing from 0.23 million in 2013 , to 3.29 million in 2018 - a more than tenfold increase in five years (International Energy Agency [IEA], 2020b).

A rapid EV deployment, however, also presents a serious waste-treatment challenge, as mounting numbers of waste batteries, if not treated properly, would release heavy metals and toxic chemicals into the natural environment, causing soil contamination and water pollution (Ordonez et al., 2016). According to the International Energy

*Corresponding author. E-mail: muyi.yang@uts.edu.au 
Agency, about 100-120 GWh of EV batteries will reach their end of technical life worldwide by 2030 , and without proper treatment, this volume of battery waste is likely to become a significant environmental liability (IEA, 2020a). While the challenge of end-of-life EV battery treatment is global, it is particularly acute in China (the country of focus of this paper), which is currently the largest EV market in the world, representing around $45 \%$ of the global EV fleet (IEA, 2020b).

Several policy initiatives, designed based on the principle of Extended Producer Responsibility (EPR), have been introduced in China, in anticipation of the impending challenge of a large and growing volume of waste batteries from EVs. These initiatives make the EV makers responsible for the entire life-cycle of the mobility batteries, especially for their take-back, recycling, and final disposal. As such, the EV makers' responsibility - financial and physical - for mobility batteries is extended to the postconsumer stage of their life cycle. This approach, as argued by its proponents, could internalise the costs of waste battery treatment into the decision-making of EV makers, thus providing them with a better incentive to design EVs and batteries in ways that could reduce the cost of waste battery treatment and encourage battery repurposing and material recycling.

The primary objective of this paper is to review the policy initiatives for promoting the treatment of waste $\mathrm{EV}$ batteries in China, with the aim of identifying potential shortcomings. This objective is premised on our argument that much of the contemporary policy debate on waste EV battery treatment has tended to view it as a technological challenge, requiring policy support for innovations targeted at, for example, improving the cost-effectiveness of lithium-ion recycling technologies (Gaines, 2014; GeorgiMaschler et al., 2012; Li et al., 2013; Ordonez et al., 2016), and redressing environmental issues that may emerge during the course of battery recycling such as, waste gas and slag produced in the pyrometallurgy process (Li et al., 2016; Xiao et al., 2017), and wastewater (containing metal ions, organics and strong acids) produced in the hydrometallurgy process (Agrawal \& Sahu, 2009; Leonzio, 2016; Muhammad \& Lee, 2019). There is a general lack of discussion on the overall policy framework for supporting the treatment of waste EV batteries most likely because of its newness in the context of the EV industry. This discussion is, however, critical, as the efficacy of the policy framework will largely determine the extent to which a well-functioning system for treating waste EV batteries can be developed.

This paper represents a point of departure from most existing studies that view waste EV battery treatment as a technological challenge, requiring policy support for innovations, in order to improve the cost-effectiveness of battery treatment technologies, and to reduce environmental impacts arising from the battery treatment process. By assessing the overall policy framework, we contend, this paper can enable useful insights on issues that policy makers may wish to consider while designing policies to improve the effectiveness of the existing policy framework for supporting waste EV battery treatment. While these insights are developed for China, they are also relevant for other developing countries undertaking the electrification of transport.

The paper is organised as follows. The next section provides a contextual backdrop on EV battery waste treatment in China. Section 2 introduces the EPR concept and its key elements. Section 3 discusses the existing policy framework, designed based on the EPR principle, for promoting EV battery waste treatment in China. Section 4 extends this discussion, with a view to identify key shortcomings of the existing policy framework. Last Section concludes this paper. It also provides some policy suggestions.

\section{Contextual backdrop}

To provide the contextual backdrop, this section outlines key issues that may affect the treatment of waste EV batteries in China. This would enhance appreciation for the arguments presented in this paper. It is also worth noting that the issues discussed in this section are selected based on a review of major existing studies on the treatment of EV battery waste in China (see Table 1).

Technological immaturity: In order to reuse or recycle waste batteries, their state of health and state of charge need to be assessed. The state of health measures "the degree to which a battery meets its initial design specifications", and the state of charge measures "the degree to which a battery is charged or discharged" (Harper et al., 2019 , p. 77). These measures provide important information for determining whether a EV battery is best suitable for reuse or recycling, and for maintaining the safety of recycling process (Rezvanizaniani et al., 2014). In most cases, these measures are developed manually, due to the significant variation in the design (cell or module physical configuration) and chemistries of EV batteries, which makes automatic sorting and assessment difficult (Arora \& Kapoor, 2018). However, this manual process is costly and requires skilled workers and specialised equipment (Elwert et al., 2018). The small pool of skilled workers for undertaking the task further compounds this problem in China (Zhang et al., 2020a).

As most waste EV batteries still retain up to $80 \%$ of their initial capacity, it has been suggested that their reuse through a hierarchy of less demanding applications (for example, behind-the-meter energy storage) could be an attractive option for optimising material use and lowering the cost of lithium-ion batteries (Institute for Energy Research [IER], 2019; Neubauer et al., 2015). Nonetheless, significant debate on the technical viability of battery reuse has been witnessed in the past few years, mainly caused by concerns about the safety and reliability of reused batteries (Baumhofer et al., 2014; Han et al., 2014; MartinezLaserna et al., 2018; Saez-De-Ibarra et al., 2016), which primarily arises from the technical difficulty in providing an accurate assessment of the "degradation behaviour" of waste EV batteries (Martinez-Laserna et al., 2018). As a 
Table 1. Waste EV battery treatment: Key issues

\begin{tabular}{|c|c|c|}
\hline & Key issues & References \\
\hline $\begin{array}{l}\text { Technological } \\
\text { immaturity }\end{array}$ & $\begin{array}{l}\text { Sorting and assessment } \\
\text { - High reliance on costly manual process } \\
\text { - Difficulty in accurately assessing the "degradation behaviour" of waste batteries } \\
\text { Recycling } \\
\text { - Pyrometallurgical process: not suitable for recycling NMC and LFP batteries } \\
\text { widely used in EVs } \\
\text { - Hydrometallurgical process: low recycling efficiency } \\
\text { - Direct recycling: not yet commercially viable } \\
\text { Repurposing } \\
\text { - Significant debate on the safety and reliability of reused batteries } \\
\text { - Concern about the technical viability of reusing waste batteries }\end{array}$ & $\begin{array}{l}\text { Zhang et al., (2020a); } \\
\text { Zhang et al. (2020b); } \\
\text { Zheng et al. (2019); } \\
\text { Qiao et al. (2019); } \\
\text { Zeng et al. (2015); Yang } \\
\text { et al. (2019); Huang } \\
\text { et al. (2018); Harper } \\
\text { et al. (2019); Han et al. } \\
\text { (2014) }\end{array}$ \\
\hline $\begin{array}{l}\text { iic } \\
\text { tiveness }\end{array}$ & $\begin{array}{l}\text { - Collection: lack of consumer willingness to treat their waste batteries through } \\
\text { qualified recyclers } \\
\text { - Recycling: poor economic viability, caused by low collection volume of waste } \\
\text { batteries, high cost of existing technologies, low content of valuable materials in } \\
\text { some batteries, significant volatility of material (e.g., cobalt, and lithium) prices, } \\
\text { and excessive recycling capacity } \\
\text { - Repurposing: poor economic viability, caused by falling cost of new batteries, } \\
\text { high cost of waste battery refurbishment, and small market for reused batteries }\end{array}$ & $\begin{array}{l}\text { Dominish et al. (2019); } \\
\text { Mayyas et al. (2018); } \\
\text { Li and Li (2020); Sun } \\
\text { (2018); D1EV (2020); } \\
\text { Orient Securities (2020) }\end{array}$ \\
\hline $\begin{array}{l}\text { Insufficient } \\
\text { treatment capacity }\end{array}$ & $\begin{array}{l}\text { - Underdeveloped capacity for handling (i.e., collecting, transporting, stockpiling, } \\
\text { sorting, dismantling, and testing) waste EV batteries } \\
\text { - Small pool of trained technicians and professional staffs capable of handling } \\
\text { waste batteries }\end{array}$ & $\begin{array}{l}\text { Zhang et al. (2020a); } \\
\text { Neubauer et al. (2015) }\end{array}$ \\
\hline $\begin{array}{l}\text { Large informal } \\
\text { sector }\end{array}$ & $\begin{array}{l}\text { - A large portion of waste batteries being treated in small, unqualified workshops, } \\
\text { where "inferior" technologies and practice are often adopted for treating waste } \\
\text { batteries, posing serious risks to personnel safety and ecological environment }\end{array}$ & $\begin{array}{l}\text { Bie (2019); Elwert et al. } \\
\text { (2018); D1EV (2018) }\end{array}$ \\
\hline $\begin{array}{l}\text { Lack of } \\
\text { standardisation in } \\
\text { battery design }\end{array}$ & $\begin{array}{l}\text { - Lack of standardisation in the design of mobility batteries, which tends to } \\
\text { complicate the process of waste battery treatment }\end{array}$ & $\begin{array}{l}\text { Engel et al. (2019); Jiang } \\
\text { et al. (2020) }\end{array}$ \\
\hline
\end{tabular}

result, the development of battery reuse technology is still in its early stages, and most of this development in China so far has been confined to a few pilot projects (Zhang et al., 2020b; Zheng et al., 2019).

There are two main technologies for recycling lithium-ion batteries, namely, pyrometallurgical process, and hydrometallurgical process (Qiao et al., 2019). So far, the hydrometallurgical process is the most widely used technology in China (Larouche et al., 2020). The main reason is that the pyrometallurgical process cannot recover some high-value materials (such as, lithium) from waste EV batteries (Georgi-Maschler et al., 2012), and it is also not suitable for recycling $\mathrm{Li}\left(\mathrm{Ni}_{\mathrm{x}} \mathrm{Co}_{\mathrm{y}} \mathrm{Mn}_{1-\mathrm{x}-\mathrm{y}}\right) \mathrm{O}_{2}(\mathrm{NMC})$ and $\mathrm{LiFePO}_{4}$ (LFP) batteries used in most of the country's EVs (Zeng et al., 2015). Furthermore, the overall recycling efficiency of the pyrometallurgical process is still low, and it is estimated that this process can only effectively recover around half of the materials from battery waste (Qiao et al., 2019; Zeng et al., 2015). One key reason for this is the technical difficulty of treating heterogeneous waste $\mathrm{EV}$ batteries with quite different physical characteristics (e.g., size, and format) and chemical compositions (Huang et al., 2018; Skeete et al., 2020).

Recent years have also witnessed the development of direct recycling technology as an alternative to the hydrometallurgical process. This technology involves the removal of cathode or anode material from the electrode for making remanufactured batteries (Harper et al., 2019). The attractiveness of this technology comes from its ability to maintain the structure, morphology, and purity of the valuable cathode materials, which are normally destroyed in the pyrometallurgical and hydrometallurgical processes (Yang et al., 2019). However, the direct recycling technology has not yet demonstrated its commercial viability as evidenced by its low efficiency of treating waste batteries with poor state of health, inflexibility of handling metal oxides of different compositions, and poor electrochemical performance (Harper et al., 2019).

Economic unattractiveness: There appears to be a general lack of willingness for EV users in China to treat their waste EV batteries through qualified recyclers. Rather, many consumers sell their battery waste to unqualified recyclers. It is quite common for these recyclers to violate the environmental regulation, and dispose dangerous toxins and heavy metals from waste batteries to landfill without proper treatment. They could therefore pay higher prices to EV users for their waste batteries (Dominish et al., 2019). This leads to a low collection volume of waste batteries for qualified recyclers, and this problem gets further exacerbated by poor consumer awareness of the importance of waste battery treatment. For qualified recyclers, a low collection volume of waste batteries means high costs of battery recycling, thus making battery recycling economically unviable (Mayyas et al., 2018). 
Other key factors, that affect the economic viability of battery recycling, include the low content of valuable materials (such as, lithium) in some waste batteries $\left(\mathrm{LiFePO}_{4}\right)$, high recycling costs incurred by most existing technologies, significant volatility of material (such as, cobalt, and lithium) prices, and excessive recycling capacity fuelled by subsidies and policy misinterpretation (DaninoPerraud, 2020; DeRousseau et al., 2017; Li \& Li, 2020). In China, the poor economic viability of waste EV battery recycling is reflected in a low recycling rate: $2 \%$ in 2015 , and 10\% in 2019 (D1EV, 2020; Sun, 2018).

For battery reuse, it is suggested that the cost gap between reused and new batteries needs to remain sufficiently wide to warrant the performance trade-off (in terms of, for example, lifetime, and reliability) in reused batteries relative to new alternatives. However, this gap is more likely to become narrower, as the cost of making new batteries is expected to decline at the rate far exceeding the rate at which the cost of making reused batteries declines, which will in turn make reused batteries less cost-competitive in the market (Engel et al., 2019). This is especially true if one notes that the cost of new EV batteries has declined by over $85 \%$ since 2010 - considerably faster than many studies initially anticipated (see, for example, Nykvist \& Nilsson, 2015). The economic viability of reusing wasted $\mathrm{EV}$ batteries gets further reduced by factors such as, high cost of existing technologies for refurbishing waste batteries (Neubauer et al., 2015), and the lack of a well-established market in China for reused batteries, despite several government initiatives to install reused batteries in different kinds of energy storage systems (most notably, backup power for telecom towers) (Orient Securities, 2020).

Insufficient treatment capacity: Having sufficient physical capacity for treating (i.e., transporting, stockpiling, sorting, dismantling, and testing) waste EV batteries is widely considered as essential for ensuring the effective treatment of waste EV batteries (Melin, 2019). This capacity is however underdeveloped in China, even though significant improvement has been made in the past few years (Zhang et al., 2020a). This underdevelopment likely reflects the technical complexity of handling hazardous waste batteries with a wide variation in their chemical compositions and physical characteristics (for example, size, and format) (Neubauer et al., 2015). An example of such complexity is provided by the selected excerpts from Harper et al. (2019):

"Disassembly of battery packs from automatic applications requires high-voltage training and insulated tools to prevent electrocution of operators or short-circuiting of the pack. Short-circuiting results in rapid discharge, which may lead to heating and thermal runaway. Thermal runaway may result in the generation of particularly noxious by-products, including HF gas, which along with other product gases may become trapped and ultimately result in cells exploding. The cells also present a chemical hazard owing to the flammable electrolyte, toxic and carcinogenic electrolyte additives, and the potentially toxic or carcinogenic electrode materials" (Harper et al., 2019, pp. 76-77).

The underdeveloped current state of the industry capacity for treating waste batteries gets further exacerbated by the lack of trained technicians and professional staff capable of undertaking the task. In response, the Ministry of Industry and Information Technology [MIIT] of China has implemented a training program for specialised technical personnel for mobility battery treatment. Despite this, it is observed that there is still a shortage of skilled personnel in the battery treatment industry, raising safety concerns about waste battery treatment (Zhang et al., 2020a).

Large informal recycling sector: As mentioned previously, a large proportion of the waste EV batteries is currently treated through small, non-qualified workshops, posing serious risks to personnel safety and ecological environment (Bie, 2019). These risks get further exacerbated if one notes the technical complexity of handling waste EV batteries, which requires highly qualified technicians and specialised tools (Elwert et al., 2018). These requirements, however, are often not fulfilled by small workshops, who are more likely to adopt "inferior" technologies and practice for treating waste batteries, in an effort to lower the overall cost of waste battery treatment (Bie, 2019). For example, it is reported that the task of treating waste $\mathrm{EV}$ batteries is often undertaken by companies who treat scrapped motor vehicles in China. Some of these companies tend to stockpile and treat waste EV batteries in places designed for treating general motor vehicles, unsuitable for treating waste EV batteries, posing potential environmental and fire risks (D1EV, 2018).

Lack of standardisation on battery design: There seems to be a general lack of standards on the design of EV batteries in China, as indicated by the availability of a large number of battery-pack designs on the market that vary significantly from each other in terms of size, format (cylindrical, prismatic, and pouch), and chemical composition. The lack of standardisation on battery design could however complicate the process of waste battery treatment (Engel et al., 2019). For example, EV batteries with different physical configurations require different approaches for disassembling and recycling. In the direct recycling process, for example, approaches for separating the planar electrodes from the batteries with prismatic and pouch cells are quite different from the batteries with cylindrical cells (Harper et al., 2019).

\section{Extended producer responsibility (EPR): Concept and key elements}

The concept of EPR has been applied globally to a variety of wastes including, for example, electrical and electronic equipment, lead acid batteries, packaging, and tyres (Leclerc \& Badami, 2020). It assigns producers the responsibility for the treatment of their used or end-of-life products (waste EV batteries, in our instance) 
(Lindhqvist, 1992). This involves the establishment of a take-back mechanism, whereby consumers return their used products to be repurposed, recycled, or disposed, under the producer's responsibility (Khetriwal et al., 2009). The attractiveness of this approach arises from its ability to internalise the costs of waste treatment into the considerations of the producers, thus providing them with a better incentive to design their products in ways that could lower the cost of waste treatment through, for example, more standardised product design (Park et al., 2018; Pouikli, 2020; Sachs, 2006). Its proponents also argue that EPR-based policies could leverage private sector funding and expertise to promote end-of-life waste treatment, and hence reduce the financial burden of waste treatment on the government (Lifset et al., 2013).

An EPR-based policy framework typically comprises four key elements (Khetriwal et al., 2009; Leclerc \& Badami, 2020; OECD, 2001). The first element is the scope of waste products to be included in the policy framework (Leclerc \& Badami, 2020). For example, the scope of the policy framework may be limited to waste batteries from EVs purely run on battery power, but may also be extended to include those from hybrid and plug-in hybrid EVs. The second element includes the targets for waste treatment (Leclerc \& Badami, 2020), which can be expressed in terms of, for example, collection and recycling rates of waste EV batteries, or material recovery rates. The third element includes the regulatory arrangements for ensuring the "quality" of waste treatment. Producers may be mandated to treat the waste products according to specific standards. They may also be required to prioritise repurposing rather than recycling in the treatment process (Leclerc \& Badami, 2020). Other stakeholders (such as, consumers) may also be mandated to fulfil their own responsibility (for example, returning waste products to authorised outlets) in the waste treatment process (Khetriwal et al., 2009).

The fourth element is the allocation of producer responsibility, which can be further divided into two subcategories, namely, the allocation of physical and financial responsibilities (Gupt \& Sahay, 2015; Leclerc \& Badami, 2020). The physical responsibility is referred to as the responsibility for the collection, transport, sorting, repurposing, recycling, and disposal of waste products. These responsibilities can be either allocated to one or several competing Producer Responsibility Organisations, who collectively treat the waste products, or to each individual producer. The producers may decide to fulfil their allocated responsibilities by themselves, or to assign all or part of them to authorised entities (e.g., specialised battery recyclers) (Fuminori et al., 2011; Khetriwal et al., 2009). The financial responsibility refers to the responsibility for financing the treatment of waste products. It can be allocated to the producers, who may choose to pass on the costs incurred by waste treatment to consumers through, for example, charging waste treatment fees at the time of purchase or when consumers return their waste products (Khetriwal et al., 2009). The government may also subsidise the waste treatment process in the forms of, for example, direct financial support, or tax benefits (OECD, 2001; Walls, 2006).

\section{EPR-based policy framework for wasted EV battery treatment in China}

This section first provides a historical review of the development of policies for supporting waste EV battery treatment in China, and then discusses the key elements of the EPR-based policy framework emerged from this development. Here, particular attention is given to four elements of this framework, namely, scope, targets for battery treatment, regulatory arrangements, and allocation of producer responsibility, as discussed in the previous section. The method adopted for this section is a review of related policy documents and regulatory standards obtained from government policy databases (see Figure 1). Some journal articles and reports are also used for augmenting discussion in the section.

\subsection{Historical development}

EV battery waste treatment was not a subject matter of priority in China until the late 2000s, as the volume of waste batteries was almost negligible, given the country's very small EV fleet (about 500 battery and plug-in hybrid EVs in 2009). The only noteworthy policies during these

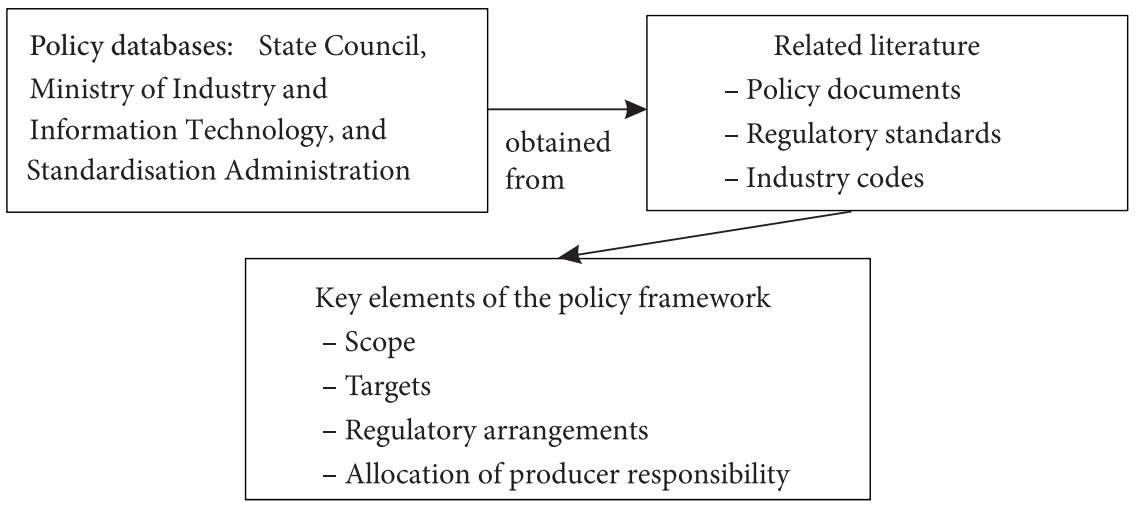

Figure 1. Method for conducting the policy review 
years were the introduction of various industry standards and codes, focused on reducing human and environmental exposure to toxic chemicals during the manufacturing process for mobility lithium-ion batteries, and on ensuring the safety of battery transportation (Zeng et al., 2015).

The early 2010s witnessed higher priority being attached to transport electrification in China, as indicated by the implementation of a range of monetary (e.g., financial subsidies, and tax exemptions) and non-monetary (such as, traffic and vehicle ownership control exemptions) incentives for promoting the uptake of electric vehicles (Li et al., 2018). Prompted by these incentives, the country's EV stock (including both battery and plugin hybrid EVs) expanded at a rapid pace over the period 2010-2019, from about 1,900 in 2010, to over 3 million in 2019 (IEA, 2020a).

In anticipation of the impending challenge of treating waste batteries from a rapidly expanding EV fleet, the Chinese government introduced several policies to promote the treatment of waste EV batteries. For example, in 2012, the State Council released the Notice of the State Council on Issuing the Planning for the Development of the Energy-Saving and New Energy Automobile Industry (2012-2020), with particular emphasis on providing the overall guidance and direction for the development of EV industry. Regarding EV batteries, such emphasis envisions the establishment of a sound system for treating waste EV batteries, the development of effective technical standards and management rules for regulating this system, and the effective enforcement of these standards and rules to prevent the release of toxic materials into the environment (State Council, 2012).

The commitment to promote the treatment of waste EV batteries was re-affirmed by the release of the Guiding Opinions of the General Office of the State Council on Accelerating Promoting and Application of New-Energy Automobiles in 2014, which highlights the need to identify effective methods (e.g., up-front deposit payment refunded upon the return of waste batteries) for promoting waste EV battery collection, and to establish a sound system for recycling and reusing waste batteries from EVs (State Council, 2014). Later in 2016, the National Development and Reform Commission [NDRC] and four other central departments and administrations jointly released the Electric Vehicle Battery Recycling Technology Policy, which specifies the development direction of various aspects (i.e., design, manufacturing, collection, stockpiling, sorting, transportation, recycling, and reuse) of waste EV battery treatment, and requires EV and battery manufacturers to be responsible for treating waste EV batteries, based on the concept of Extended Producer Responsibility (EPR) (NDRC, 2016).

In order to implement the above-noted policies, a range of national standards and codes have been introduced over the period 2015-2020, for regulating various aspects (for example, safety, testing, recycling, reuse, and disposal)

Table 2. Industry standards and codes for waste EV battery treatment (source: Standardisation Administration of China 2020)

\begin{tabular}{|c|c|c|}
\hline Issuing Time & Standards and Codes & Issuer \\
\hline Feb 2015 & Zinc-air batteries for electric road vehicle: GB/T 1833.2-2015 & SAC \\
\hline May 2015 & $\begin{array}{l}\text { Lithium-ion traction battery pack and system for electric vehicles } \\
\text { Part 1: Test specification for high power applications, GB/T 31467.1-2015 } \\
\text { Part 2: Test specification for high energy applications, GB/T 31467.2-2015 } \\
\text { Part 3: Safety requirements and test methods, GB/T 31467.3-2015 }\end{array}$ & SAC \\
\hline May 2015 & Life cycle requirements and test methods for traction battery of electric vehicle: GB/T 31484-2015 & SAC \\
\hline May 2015 & Safety requirements and test methods for traction battery of electric vehicle: GB/T 1485-2015 & SAC \\
\hline May 2015 & $\begin{array}{l}\text { Electrical performance requirements and test methods for traction battery of electric vehicle: } \\
\text { GB/T 31486-2015 }\end{array}$ & SAC \\
\hline May 2017 & $\begin{array}{l}\text { Aluminium and aluminium alloys plates, sheets, and strips for cans and caps of new energy power } \\
\text { batteries: GB/T 33824-2017 }\end{array}$ & SAC \\
\hline May 2017 & $\begin{array}{l}\text { Recycling of traction battery used in electric vehicle - Dismantling specification: GB/T 33598.2- } \\
2017\end{array}$ & SAC, GAQSIQ \\
\hline July 2017 & Coding regulation for automotive traction battery: GB/T 34014-2017 & SAC, GAQSIQ \\
\hline July 2017 & Dimension of traction battery for electric vehicles: GB/T 4013-2017 & SAC, GAQSIQ \\
\hline July 2017 & Recycling of traction battery used in electric vehicle - Test of residual capacity: GB/T 34015-2017 & SAC, GAQSIQ \\
\hline March 2020 & Technical specifications of battery management system for electric vehicles: GB/T 38661-2020 & SAC, SAMR \\
\hline March 2020 & $\begin{array}{l}\text { Recycling of traction battery used in electric vehicle } \\
\text { Part 1: Packing and transporting, GB/T 38698.1-2020 } \\
\text { Part 2: Materials recycling requirements, GB/T 33598.2-2020 }\end{array}$ & SAC, SAMR \\
\hline March 2020 & $\begin{array}{l}\text { Recycling of traction battery used in electric vehicle - Echelon use Part 2: Removing } \\
\text { requirements, GB/T 34015.2-2020 }\end{array}$ & SAC, SAMR \\
\hline May 2020 & Electric vehicles traction battery safety requirements: GB 38031-2020 & SAC, SAMR \\
\hline
\end{tabular}

Notes: SAC - Standardisation Administration of China; GAQSIQ - The General Administration of Quality Supervision, Inspection and Quarantine; SAMR - State Administration for Market Regulation. 
of waste battery treatment (see Table 2 for details). These standards and codes can be either mandatory (GB) or voluntary $(\mathrm{GB} / \mathrm{T})$. According to the Standardisation Law of the People's Republic of China, mandatory standards are technical requirements designed for "safeguarding human health and the safety of the person, state security, ecological environment security, and meeting fundamental needs of social and economic administration" (Article 9), and voluntary standards are technical requirements "necessary for supporting mandatory standards, and leading the relevant industries" (Article 10).

The Interim Measures for the Management of Recycling and Utilisation of Power Batteries of New Energy Vehicles (thereafter, the Interim Measures), endorsed in 2018, further consolidates existing policies and regulations for EV battery waste treatment, and provides an overall policy framework for promoting EV battery waste treatment, compatible with the country's aspiration for transport electrification. Key aspects of the Interim Measures are: 1) EV makers are made responsible for EV battery waste treatment, based on the EPR concept; 2) battery manufacturers are encouraged to design batteries in ways that are easy to disassemble, and they are also mandated to provide technical details required for the end-of-life battery treatment to EV makers; 3) cascaded application of waste EV batteries are encouraged; and 4) the Ministry of Industry and Information Technology [MIIT] and other relevant departments are made responsible for further progressing the standardisation of waste battery treatment, and for implementing an information system for regulating this process (MIIT, 2018c).

For implementing the Interim Measures, the MIIT and other six central ministries and commissions jointly announced in 2018 the pilot programs for promoting the recycling and reuse of waste EV batteries in BeijingTianjin-Hebei, Yangtze River Delta, Pearl River Delta, and Central regions (MIIT, 2018b). A traceability management system also became operational in the year, wherein information for each EV battery is recorded and updated by all relevant stakeholders (e.g., battery manufacturers, $\mathrm{EV}$ makers, car dealers, reuse companies, and recyclers). The implementation of this system is aimed at collecting information of EV batteries, covering their entire lifecycle, from manufacturing through to sales, use, dismantling, recycling/reuse, and disposal, for the regulation of waste battery treatment (MIIT, 2018a).

\subsection{Key elements of the policy framework}

As discussed above, the need for EV battery waste treatment was not felt in China until the late 2000s, as the numbers of waste batteries from a very small EV fleet were almost negligible. The situation began to change in the early-to-mid 2010s, as a rapid uptake of EVs, fuelled by a range of monetary and non-monetary incentives, promoted the national policy makers to consider ways of redressing the waste-treatment issue posed by a rapidly growing EV fleet. This resulted in the introduction of several policies for promoting EV battery waste treatment. Recent years also witnessed some efforts to consolidate these policies, with a view to provide an overall framework for promoting and managing EV battery waste treatment. This framework is largely devised based on the EPR concept, and the onus is placed on EV makers to facilitate battery waste treatment. Key elements of this framework are presented in Table 3, and further details are provided below.

Scope and targets: The EPR-based framework currently covers waste mobility batteries from all "new energy vehicles" including plug-in hybrid electric vehicles (PHEVs), and battery electric vehicles (BEVs) (MIIT, 2020). It also sets out targets for the treatment of waste EV batteries regarding material recovery, for each individual battery recycler. These targets are set at $98 \%$ for nickel, cobalt, and manganese, $85 \%$ for lithium-ion, and $97 \%$ for rare earth elements and other metals (MIIT, 2019b).

Regulatory arrangements: A range of national and industry standards has been introduced to regulate various aspects (e.g., technical, safety and environmental) of the process of EV battery waste treatment (see Table 2 for details). Their administration and enforcement is a shared responsibility between several central (e.g., MIIT, and SAMR) and local agencies, whose scope of authority is not explicitly defined. For example, as stipulated in the Interim Measures, the MIIT and the General Administration of Quality Supervision, Inspection and Quarantine (GAQSIQ, now part of the SAMR) are responsible for developing a traceability management system for waste EV batteries, and for establishing, together with the Ministry of Ecology and Environment, the Ministry of Transport, the Ministry of Commerce, and other relevant departments, an information sharing mechanism, to ensure effective management of mobility batteries over their entire life cycle (MIIT, 2018c). There is no clear definition of the scope of authority among these departments in assuming their joint responsibility nor explicit guidelines for managing inter-institutional relationships.

Allocation of producer responsibility: According to the Interim Measures introduced in 2018, it is the responsibility of the EV makers to establish waste battery collection outlets and to transport collected batteries to relevant companies for treatment (MIIT, 2018c). Interestingly though, in the Guide to the Construction and Operation of New Energy Vehicle Power Battery Recycling Service Outlets introduced more recently, both EV makers and cascaded application companies are made responsible for establishing waste battery collection outlets; they can fulfil this responsibility by either establishing their own or joint outlets, or assigning the task to authorised entities. EV makers are also made responsible to work with battery makers, recyclers, and cascaded application companies in the repurposing, recycling, and disposal of waste batteries used in their EVs (MIIT, 2019a). In addition, the funding mechanisms for waste battery treatment are not explicitly specified in the current policy framework. 
Table 3. Key elements of the policy framework

(sources: Developed by the authors based on a review of MIIT, 2018a, 2019a, 2019b, 2020)

\begin{tabular}{|l|l|}
\hline & \multicolumn{1}{c|}{ Key features } \\
\hline Scope & $\begin{array}{l}\text { Waste mobility batteries from New Energy Vehicles (including hybrid vehicles, and battery EVs) } \\
\text { Batteries scrapped after cascaded applications and during the manufacturing process are also included } \\
\text { Lead acid batteries are not included }\end{array}$ \\
\hline Targets & $\begin{array}{l}\text { Composite recovery rate of nickel, cobalt, and manganese: } \geq 98 \% \\
\text { Lithium-ion recovery rate: } \geq 85 \% \\
\text { Composite recovery rate of rare earth elements and other metals: } \geq 97 \% \\
\text { Material recovery rate: } \geq 90 \% \text { (using material repair technologies) }\end{array}$ \\
\hline $\begin{array}{l}\text { Regulatory } \\
\text { arrangements }\end{array}$ & $\begin{array}{l}\text { National and industry standards for governing the testing, storage, transportation, recycling, repurposing, and } \\
\text { disposal of waste EV batteries (see Table 1 for details), implemented and enforced by a range of central (e.g., MIIT, } \\
\text { MEE, and SAMR) and local agencies } \\
\text { MIIT responsible for developing and implementing a battery traceability management system }\end{array}$ \\
\hline $\begin{array}{l}\text { Allocation } \\
\text { of producer } \\
\text { responsibility }\end{array}$ & $\begin{array}{l}\text { Physical responsibility } \\
\text { Collection: EV makers and cascaded battery application firms } \\
\text { Treatment: EV makers are encouraged to work with battery makers, recyclers, and cascaded application companies } \\
\text { in the repurposing, recycling, and disposal of waste batteries used in their EVs } \\
\text { Financial responsibility } \\
\text { Mechanisms for financing waste battery treatment not explicitly specified }\end{array}$ \\
\hline
\end{tabular}

Notes: MIIT - Ministry of Industry and Information Technology; MEE - Ministry of Ecology and Environment; SAMR - State Administration for Market Regulation.

\section{Discussion}

Based on the policy review conducted in the previous section, this section discusses some of the major shortcomings of the existing policy framework for EV battery waste treatment in China.

Lack of provisions for historical and orphan batteries: It has not been specified whether historical and orphan batteries are included in the scope of the current policy framework. Historical batteries refer to waste batteries from EVs that have been sold prior to the implementation of the current policy framework, and orphan batteries refer to waste batteries from EVs whose manufacturers have ceased to exist. Though no reliable publicly available data on historical and orphan batteries exists in the Chinese EV market, it can be anticipated that this issue will become more pronounced in the next couple of years. As the government has started to cut EV subsidies since 2017, many EV makers (especially some loss-making EV start-ups) have struggled to survive in the face of intensifying competition (Cui, 2017; Hancock, 2019). As a result, China's EV sales recorded its first-ever annual decline to 1.1 million units in 2019 , down $6 \%$ compared to the year prior (IEA, 2020a). The situation has become even worse this year, as the lockdown measures, though successfully getting the Covid-19 outbreak under control rapidly, have also significantly affected EV sales. It is reported that many EV makers have been struggling to keep afloat with substantial drops in their car sales (Udemans \& Shen, 2020). If some of these EV makers enter bankruptcy, their EVs and batteries will become orphan products.

No target on battery collection: The current policy framework, as discussed in the previous section, only sets targets for material recovery from waste EV batteries. There is no target for the overall collection of waste batteries. This target is however important especially if one notes the current underdeveloped state of battery treatment capacity in China. This, together with the significant technological immaturity of battery waste treatment, as discussed in section 2, means that the main policy priority at the moment is to promote innovations in the technology, process and practice of EV battery waste treatment, and to encourage their successful industrialisation. It is impractical to expect a large uptake of battery treatment capacity in the short-run. Hence, a battery collection target should be set to guide the gradual development of capacity for waste battery treatment by, for example, first requiring full collection and safe stockpiling of waste batteries from EVs, and gradually increasing the treatment rate, as the industry scales up its capacity for waste battery treatment.

Unclear definition of the scope of authority: Ensuring the treatment of waste EV batteries through qualified channels is a difficult task in China, especially in the presence of a large informal recycling sector, as discussed in section 2. Unqualified recyclers do not have to pay the costs associated with complying with safety and environmental regulations, and can offer EV users high bids for their wasted batteries. Therefore, EV users are likely to be misguided about the remaining value of their batteries, opting to recycle them through unqualified recyclers. The unfair competition from the informal sector can however suppress the uptake of qualified facilities for treating waste EV batteries. This issue has already been recognised by the government, and a range of regulatory standards has been introduced in the past few years to govern the process of waste battery treatment. The actual outcome, to a larger extent, depends on their effective administration and enforcement, which is a shared responsibility between several central (e.g., MIIT, and SAMR) and local agencies. There is no clear definition of the scope of authority 
among these agencies nor explicit guidelines for managing inter-institutional relationships (see section 4). This arrangement may, however, lead to poor regulatory administration and enforcement. This viewpoint gets substantiated by the recent EV subsidy fraud, where poor program auditing and enforcement has been identified as the key factor responsible for false reporting by large EV makers, in order to receive the subsidies (Cui, 2017).

Insufficient regulatory requirements for data auditing and verification: For a policy to deliver its expected outcomes, effective data collection and audit is required, because this will enable the assessment of the progress of the policy endeavour and issues that may affect its effectiveness. In the context of EV battery treatment, the MIIT has launched a traceability management system in 2018, wherein information for each battery is recorded and updated by all relevant stakeholders (e.g., battery manufacturers, EV makers, car dealers, reuse companies, and recyclers), aimed at collecting data and information regarding the entire life cycle of EV batteries from production to disposal (see section 4). The implementation of this system is governed by the Interim Measures for the Traceability Administration of Recycling Traction Batteries of New Energy Vehicles, where there is no clear requirement for data auditing and verification (MIIT, 2018a). This system just became operational recently, and there is a lack of reliable data and information in the public domain that can be used to examine its data quality. Despite this, it is still reasonable to argue that the absence of clear requirements for data auditing and verification is a loophole and can undermine the overall effectiveness of the traceability management system.

Uncooperative stakeholders: As discussed in the previous section, the existing policy framework for waste EV battery treatment is devised based on the EPR concept, and the onus is placed on EV makers to facilitate waste battery treatment by, for example, establishing service outlets through which waste batteries can be collected, sorted, and transported to specialist recyclers or repurposers. To fulfil their responsibility, EV makers need to work closely with other relevant stakeholders (e.g., users, transporters, recyclers, battery manufacturers, re-purposed battery users, and government) involved in the process of the collection, testing, sorting, transportation, recycling, repurposing, and disposal of waste batteries. It is sometimes challenging for EV makers to ensure the cooperation of relevant stakeholders. For example, several studies pointed out that while some kinds of reward-penalty mechanisms are put in place to encourage consumer participation in waste battery treatment (Tang et al., 2018; Viscusi et al., 2011), these mechanisms are difficult to enforce. This difficulty gets substantiated if one notes the lack of consumer willingness to treat their waste EV batteries through qualified recyclers in China, despite the inclusion of a take-back clause in their EV purchase agreements that require them to treat waste batteries through qualified channels.
No explicit specification on financing mechanisms: Incentives for EV battery recycling and repurposing have been limited, due to factors, such as, significant technological immaturity, small market for reused batteries with falling cost of new batteries and high cost of battery refurbishment, and poor economic viability for recycling, caused by low collection volume of waste batteries, high cost of existing technologies, low content of valuable materials in some batteries, significant volatility of material (e.g., cobalt, and lithium) prices, and excessive recycling capacity (see details in section 2). This means that some mechanisms are required for subsidising the development of EV battery waste treatment. This involves the setting up of treatment fees collected from EV users to cover the gap between the total system cost and the total recovered value from the waste batteries. These fees can be collected at the time of purchase or when EV users return their batteries for treatment. The government may also decide to subsidise the battery treatment process in the forms of, for example, direct financial support, or tax benefits. The financing mechanisms are however not explicitly specified in the current policy framework, and it is left to the EV makers to decide on their own financing mechanisms for waste battery treatment. Ineffective cost recovery may lead to additional financial burden on EV makers, who are currently struggling to keep afloat given recent substantial declines in their vehicle sales.

\section{Conclusions and policy suggestions}

As discussed in this paper, an EPR-based policy framework has been put in place by the Chinese government for redressing the impending challenge of a large and growing volume of battery waste from EVs. This framework places the responsibility of facilitating waste battery treatment on EV makers, with a view to internalise the costs of waste battery treatment into their decision-making, thus providing them with a better incentive to design electric vehicles and batteries in ways that could reduce the cost of wasted battery treatment. While a very significant step forward, this policy framework still suffers from several major shortcomings: 1) no provisions for historical and orphan batteries in the policy framework, indicating a major gap in the coverage of waste batteries; 2) no target on battery collection; 3) no clear definition of the scope of authority among various central and local agencies involved in the administration and enforcement of regulatory standards on battery treatment nor explicit guidelines for managing inter-institutional relationships; 4) a lack of clear requirements and provisions for data auditing and verification for tracking the entire life cycle of EV batteries; 5) limited consideration of the challenges to ensure cooperation of all relevant stakeholders in the waste battery treatment process; and 6) no explicit specification of the mechanisms for financing waste battery treatment.

Accordingly, this paper suggests that redressing the impending challenge of waste EV batteries in China will 
hinge upon some significant improvements or adjustments of the existing EPR-based policy framework such as the following. Historical and orphan batteries should be included in the scope of the policy framework. Otherwise, they may be recycled through unqualified channels, or even end up in landfill, posing potential environmental and safety risks. In practice, however, the inclusion of them will be hugely problematic, especially in regard to who will be responsible for treating them. The government may consider assigning this responsibility to a collective producer organisation or a few select individual producers. The government should also cover the total costs associated with the treatment of these batteries through, for example, tax levies on all EV users. Competitive bidding may also be considered for the treatment of these batteries, to reduce the treatment costs.

A target should be set on waste battery collection, to ensure full collection and safe stockpiling of waste batteries from EVs, especially in the backdrop of the current underdeveloped state of battery treatment capacity in China, which is unlikely to be improved in the near future, due mainly to the technological immaturity of battery waste treatment, as discussed in section 2. This target can be intended at the national level, leaving more freedom for the industry to choose where to concentrate efforts, or at the provincial or local level.

The government may consider strengthening the current regulatory arrangements for the treatment of waste EV batteries by, for example, clearly defining the scope of authority among various central and local agencies in the regulatory process, introducing some mechanisms for managing inter-institutional relationships, and making clear requirements and provisions for data auditing and verification. The government may also consider making a clear and fair allocation of responsibilities among all relevant stakeholders, and introducing some reward-penalty mechanisms, in order to ensure their cooperation in the process of waste battery treatment. In order to ensure the financially viability of waste battery treatment, and to prevent placing too much financial burden on EV makers, the government may also like to consider providing clearer specifications on the financing mechanisms, especially in case the total value recovered from waste batteries is insufficient to cover the total costs of their treatment.

Further, given the real-world complexity and uncertainty common to nearly all policy spheres, this paper suggests that the development of policies for supporting the treatment of waste EV batteries should be an iterative process, wherein the policy outcomes are evaluated and re-evaluated, in order to identify issues emerging over the course of policy implementation as well as ways to redress them. The MIIT - the apex body for policy formulation and decision-making in the area of transport electrification - should assume such a responsibility. A task force, chaired by MIIT, should be established, with membership from all actors involved in the treatment of waste EV batteries. This task force will be empowered to periodically review the battery treatment policies, and advise the MIIT on the need for revisiting their specific elements.

The analysis conducted in this paper is qualitative in nature. This analysis is useful, due to its ability to identify some of the key shortcomings of the existing policy framework for supporting the treatment of waste EV batteries in China. The usefulness of this analysis can be augmented if some quantitative analysis can also be undertaken to lend credence to the insights gained from it, not just confined to select examples or historical events. It is however difficult to undertake such an analysis, due to the limited availability of reliable data and information in the public domain required for quantitatively assessing the effectiveness of waste EV battery treatment policies. This is probably because of the newness of the issue of waste batteries in the context of EV industry. It would be highly beneficial if a system of data collection could be established to enable future quantitative analysis to be undertaken on the issue of waste EV battery treatment.

\section{Acknowledgements}

This work was supported by the National Natural Science Foundation of China (No. 71904067) and Collaborative Research Project (CRP) between University of Technology Sydney and Commonwealth Scientific and Industrial Research Organisation (No. C022084).

\section{References}

Agrawal, A., \& Sahu, K. K. (2009). An overview of the recovery of acid from spent acidic solutions from steel and electroplating industries. Journal of Hazardous Materials, 171(1-3), 61-75. https://doi.org/10.1016/j.jhazmat.2009.06.099

Arora, S., \& Kapoor, A. (2018). Mechanical design and packaging of battery packs for electric vehciles. In G. Pistoia \& B. Liaw (Eds.), Behaviour of Lithium-ion batteries in electric vehicles (pp. 175-200). Green Energy and Technology. Springer. https://doi.org/10.1007/978-3-319-69950-9_8

Baumhofer, T., Bruhl, M., Rothgang, S., \& Sauer, D. U. (2014). Production caused variation in capacity aging trend and correlation to initial cell performance. Journal of Power Sources, 247, 332-338. https://doi.org/10.1016/j.jpowsour.2013.08.108

Bie, F. (2019, December 02). Beware of battery recycling "bad money drives out good money". China Energy News. People's Daily. China. http://paper.people.com.cn/zgnyb/html/201912/02/content_1959820.htm

Cui, H. (2017). Subsidy fraud leads to reforms for China's EV market. The International Council on Clean Transportation (ICCT). United States.

D1EV. (2018). Eight policy suggestions on electric vehcile battery recycling. China. https://www.d1ev.com/kol/61706

D1EV. (2020). Fatal battery: Why is $90 \%$ of the wasted battery missing? China. https://www.d1ev.com/news/shichang/117419

Danino-Perraud, R. (2020). The recycling of lithium-ion batteries: A strategic pillar for the European Battery Alliance. The Institut francais des relations internationales (IFRI), France.

DeRousseau, M., Gully, B., Taylor, C., Apelian, D., \& Wang, Y. (2017). Repurposing used electric car batteries: A review of options. The Journal of the Minerals, Metals \& Materials Society (TMS), 69, 1575-1582.

https://doi.org/10.1007/s11837-017-2368-9 
Dominish, E., Teske, S., \& Florin, N. (2019). Responsible minerals sourcing for renewable energy. Institute for Sustainable Futures, Sydney.

Elwert, T., Romer, F., Schneider, K., Hua, Q., \& Buchert, M. (2018). Recycling of batteries from electric vehicles. In G. Pistoia \& B. Liaw (Eds.), Behaviour of Lithium-ion batteries in electric vehciles (pp. 289-321). Green Energy and Technology. Springer. https://doi.org/10.1007/978-3-319-69950-9_12

Engel, H., Hertzke, P., \& Siccardo, G. (2019). Second-life EV batteries: The newest value pool in energy storage. McKinsey \& Company.

Fuminori, T., Boyaci, T., \& Verter, V. (2011). An analysis of monopolistic and competitive take-back schemes for WEEE recycling. Production and Operations Management, 20(6), 805-823. https://doi.org/10.1111/j.1937-5956.2010.01207.x

Gaines, L. (2014). The future of automotive lithium-ion battery recycling: Charting a sustainable course. Sustainable Materials and Technologies, 1-2, 2-7.

https://doi.org/10.1016/j.susmat.2014.10.001

Georgi-Maschler, T., Friedrich, B., Weyhe, R., Heegn, H., \& Rutz, M. (2012). Development of a recycling process for Liion batteries. Journal of Power Sources, 207, 173-182. https://doi.org/10.1016/j.jpowsour.2012.01.152

Gupt, Y., \& Sahay, S. (2015). Review of extended producer responsibility: A case study approach. Waste Management \& Research, 33(7), 595-611. https://doi.org/10.1177/0734242X15592275

Han, L., He, D., Liu, A., \& Ma, D. (2014). Adcances in secondary use research of power li-ion battery. Chinese Journal of Power Sources, 38, 548-550.

Hancock, T. (2019). Bankruptcing and slowdown hang over China's electric car market. Financial Times.

https://www.ft.com/content/1ed039c8-7e14-11e9-81d2f785092ab560

Harper, G., Sommerville, R., Kendrick, E., Driscoll, L., Slater, P., Stolkin, R., Walton, A., Christensen, P., Heidrich, O., Lambert, S., Abbott, A., Ryder, K., Gaines, L., \& Anderson, P. (2019). Recycling lithium-ion batteries from electric vehicles. Nature, 575, 75-86. https://doi.org/10.1038/s41586-019-1682-5

Huang, B., Pan, Z., Su, X., \& An, L. (2018). Recycling of lithiumion batteries: Recent advances and perspectives. Journal of Power Sources, 399, 274-286.

https://doi.org/10.1016/j.jpowsour.2018.07.116

International Energy Agency. (2020a). Global EV Outlook 2020. International Energy Agency, Paris.

https://www.iea.org/reports/global-ev-outlook-2020

International Energy Agency. (2020b). Transport: Improving the sustainability of passenger and freight transport. International Energy Agency, Paris. https://www.iea.org/topics/transport

Institute for Energy Research. (2019). The afterlife of electric vehicles: Battery recycling and repurposing. Institute for Energy Research, Washington D.C. https://www.instituteforenergyresearch.org/renewable/the-afterlife-of-electric-vehiclesbattery-recycling-and-repurposing/

Jiang, D., Su, C., Fang, S., Yuan, R., \& Chang, G. (2020). China's wasted mobility battery recycling industry: Current status and policy measures. Auto Time. China.

Khetriwal, D. S., Kraeuchi, P., \& Widmer, R. (2009). Producer responsibility for e-waste management: Key issues for consideration - learning from the Swiss experience. Journal of Environmental Management, 90(1), 153-165. https://doi.org/10.1016/j.jenvman.2007.08.019

Larouche, F., Tedjar, F., Amouzegar, K., Houlachi, G., Bouchard, P., Demopoulos, G. P., \& Zaghib, K. (2020). Progress and status of hydrometallurgical and direct recycling of li-ion batteries and beyond. Materials, 13(3), 801.

https://doi.org/10.3390/ma13030801

Leclerc, S. H., \& Badami, M. G. (2020). Extended producer responsibility for E-waste management: Policy drivers and challenges. Journal of Cleaner Production, 251, 119657. https://doi.org/10.1016/j.jclepro.2019.119657

Leonzio, G. (2016). Recovery of metal sulphates and hydrochloric acid from spent pickling liquors. Journal of Cleaner Production, 129, 417-426. https://doi.org/10.1016/j.jclepro.2016.04.037

Li, J., Wang, G., \& Xu, Z. (2016). Environmentally-friendly oxygen-free roasting/wet magnetic separation technology for in situ recycling cobalt, lithium carbonate and graphite from spent $\mathrm{LiCoO}_{2}$ /graphite lithium batteries. Journal of Hazardous Materials, 302, 97-104. https://doi.org/10.1016/j.jhazmat.2015.09.050

Li, K., \& Li, Z. (2020). Electric vehcile battery recycling in China: Current status, emerging issues and policy suggestions. EnergyTrend, China.

Li, L., Dunn, J. B., Zhang, X. X., Gaines, L., Chen, R. J., Wu, F., \& Amine, K. (2013). Recovery of metals from spent lithium-ion batteries with organic acids as leaching reagents and environmental assessment. Journal of Power Sources, 233, 180-189. https://doi.org/10.1016/j.jpowsour.2012.12.089

Li, W., Yang, M., \& Sandu, S. (2018). Electric vehicles in China: A review of current policies. Energy \& Environment, 29(8), 1512-1524. https://doi.org/10.1177/0958305X18781898

Lifset, R., Atasu, A., \& Tojo, N. (2013). Extended producer responsibility: National, International, and practical perspectives. Journal of Industrial Ecology, 17(2), 162-166. https://doi.org/10.1111/jiec.12022

Lindhqvist, T. (1992). Extended producer responsibility as a strategy to promote cleaner products. Lund University.

Martinez-Laserna, E., Gandiaga, I., Sarasketa-Zabala, E., Badeda, J., Stroe, D. I., Swierczynski, M., \& Goikoetxea, A. (2018). Battery second life: Hype, hope or reality? A critical review of the state of the art. Renewable and Sustainable Energy Reviews, 93, 701-718. https://doi.org/10.1016/j.rser.2018.04.035

Mayyas, A., Steward, D., \& Mann, M. (2018). The case for recycling: Overview and challenges in the material supply chain for automotive li-ion batteries. Sustainable Materials and Technologies, 17, e00087.

https://doi.org/10.1016/j.susmat.2018.e00087

Melin, E. (2019). State-of-the-art in reuse and recycling of lithium-ion batteries - A research review. Circular Energy Storage, Sweden.

Ministry of Industry and Information Technology. (2018a). Interim measures for the traceability administration of recycling traction batteries of new energy vehicles. Ministry of Industry and Information Technology, Beijing.

Ministry of Industry and Information Technology. (2018b). Notice on organising and lanuching the pilot program of recycling traction batteries of new energy vehicles. Ministry of Industry and Information Technology, Beijing.

http://www.gov.cn/xinwen/2018-03/05/content_5270958.htm

Ministry of Industry and Information Technology. (2018c). Notice on the release of the interim measures for the management of recycling and utilisation of power batteries of new energy vehicles. Ministry of Industry and Information Technology, Beijing.

http://www.gov.cn/xinwen/2018-02/26/content_5268875.htm

Ministry of Industry and Information Technology. (2019a). Guide to the construction and operation of new energy vehicle 
power battery recycling service network. Ministry of Industry and Information Technology, Beijing.

http://www.gov.cn/xinwen/2019-11/08/content_5450006.htm

Ministry of Industry and Information Technology. (2019b). Requirements of the industry standards for the comprehensive utilisation of waste power storage batteries of new energy vehicles. Ministry of Industry and Information Technology, Beijing. https://www.miit.gov.cn/n1146285/n1146352/n3054355/ n3057542/n3057544/c7595145/part/7595160.pdf

Ministry of Industry and Information Technology. (2020). Provisions on the access administration of new energy vehicle manufacturers and products. Ministry of Industry and Information Technology, Beijing.

http://www.gov.cn/xinwen/2020-08/19/content_5535780.htm

Muhammad, Y., \& Lee, W. (2019). Zero-liquid discharge (ZLD) technology for resource recovery from wastewater: A review. Science of the Total Environment, 681, 551-563. https://doi.org/10.1016/j.scitotenv.2019.05.062

National Development and Reform Commission. (2016). Electric vehicle battery recycling technology policy. National Development and Reform Commission, Beijing. https://www.ndrc. gov.cn/xxgk/zcfb/gg/201601/t20160128_961147.html

Neubauer, J., Smith, K., Wood, E., \& Pesaran, A. (2015). Identifying and overcoming critical barriers to widespread second use of PEV batteries. National Renewable Energy Laboratory, United States. https://doi.org/10.2172/1171780

Nykvist, B., \& Nilsson, M. (2015). Repaidly falling costs of battery packs for electric vehicles. Nature Climate Change, 5, 329-332. https://doi.org/10.1038/nclimate2564

OECD. (2001). Extended producer responsibility: A guidance manual for governments. Organisation for Economic Cooperation and Development, Paris.

https://doi.org/10.1787/9789264189867-en

Ordonez, J., Gago, E. J., \& Girard, A. (2016). Processes and technologies for the recycling and recovery of spent lithiumion batteries. Renewable and Sustainable Energy Reviews, 60, 195-205. https://doi.org/10.1016/j.rser.2015.12.363

Orient Securities. (2020). Mobility battery recycling. China.

Park, J., Diaz-Posada, N., \& Mejia-Dugand, S. (2018). Challenges in implementing the extended producer responsibility in an emerging economy: The end-of-life tire management in Colombia. Journal of Cleaner Production, 189, 754-762. https://doi.org/10.1016/j.jclepro.2018.04.058

Pouikli, K. (2020). Concretising the role of extended producer responsibility in European Union waste law and policy through the lens of the circular economy. ERA Forum, 20, 491-508. https://doi.org/10.1007/s12027-020-00596-9

Qiao, Q., Zhao, F., Liu, Z., \& Hao, H. (2019). Electric vehicle recycling in China: Economic and environmental benefits. Resources, Conservation \& Recycling, 140, 45-53.

https://doi.org/10.1016/j.resconrec.2018.09.003

Rezvanizaniani, S. M., Liu, Z., Chen, Y., \& Lee, J. (2014). Review and recent advances in battery health monitoring and prognostics technologies for electric vehcile (EV) safety and mobility. Journal of Power Sources, 256, 110-124. https://doi.org/10.1016/j.jpowsour.2014.01.085

Sachs, N. (2006). Planning the funeral at the birth: Extended producer responsibility in the European Union and the United States. Harvard Environmental Law Review, 30, 51-98.

Saez-De-Ibarra, A., Martinez-Laserna, E., Stroe, D. I., Swierczynski, M., \& Rodriguez, P. (2016). Sizing study of second life li-ion batteries for enhancing renewable energy grid in- tegration. IEEE Transactions on Industrial Application, 52(6), 4999-5007. https://doi.org/10.1109/TIA.2016.2593425

Skeete, J.-P., Wells, P., Dong, X., Heidrich, O., \& Harper, G. (2020). Beyond the EVend horizon: Battery waste, recycling, and sustainability in the United Kingdom electric vehicle transition. Energy Research and Sociel Science, 69, 101581. https://doi.org/10.1016/j.erss.2020.101581

Standardisation Administration of China. (2020). The database of national standards. China.

State Council. (2012). Notice of the State Council on issuing the planning for the development of the energy-saving and new energy automobile industry (2012-2020). Beijing.

State Council. (2014). Guiding opinions of the general office of the State Council on accelerating promotion and application of new-energy automobiles. Beijing.

Sun, G. (2018, Septermber 06). Resolving the development problems of the electric vehcile battery industry. Economic Times. Xinhua, China. http://www.xinhuanet.com/energy/201809/06/c_1123386687.htm

Tang, Y., Zhang, Q., Li, Y., Wang, G., \& Li, Y. (2018). Recycling mechanisms and policy suggestions for spent electric vehicles' power battery - A case of Beijing. Journal of Cleaner Production, 186, 388-406.

https://doi.org/10.1016/j.jclepro.2018.03.043

Udemans, C., \& Shen, J. (2020). Nio lives! How Nio (and the EV sector) rose, fell, and are getting bailed out. TechNode, China.

Viscusi, W. K., Huber, J., \& Bell, J. (2011). Promoting recycling: private values, social norms, and economic incentives. American Economic Review, 101(3), 65-70.

https://doi.org/10.1257/aer.101.3.65

Walls, M. (2006). Extended producer responsibility and product design: Economic theory and selected case studies (RFF Discussion Paper No. 06-08). Paris. https://doi.org/10.2139/ssrn.901661

Wang, S., \& Ge, M. (2019). Everthing you need to know about the fastest-growing source of global emissions: Transport. World Resource Institute, United States.

Xiao, J., Li, J., \& Xu, Z. (2017). Recycling metals from lithiumion battery by mechanical separation and vacuum metallurgy. Journal of Hazardous Materials, 338, 124-131. https://doi.org/10.1016/j.jhazmat.2017.05.024

Yang, T., Lu, Y., Li, L., Ge, D., Yang, H., Leng, W., Zhou, H., Han, X., Schmidt, N., Ellis, M., \& Li, Z. (2019). An effective relithiation process for recycling lithium-ion battery cathode materials. Advanced Sustainable Systems, 4(1), 1900088. https://doi.org/10.1002/adsu.201900088

Zeng, X., Li, J., \& Liu, L. (2015). Solving spent lithium-ion battery problems in China: Opportunities and challenges. Renewable and Sustainable Energy Reviews, 52, 1759-1767. https://doi.org/10.1016/j.rser.2015.08.014

Zhang, H., Huang, J., \& Shen, D. (2020a, February 17). Improvements required for the recycling system of wasted electric vehcile battery. China Energy News. People's Daily. China. http://paper.people.com.cn/zgnyb/html/2020-02/17/content_1971744.htm

Zhang, L., Liu, Y., Pang, B., Sun, B., \& Kokko, A. (2020b). Second use value of China's new energy vehicle battery: A view based on multi-scenario simulation. Sustainability, 12(1), 341. https://doi.org/10.3390/su12010341

Zheng, X., Lin, Z., Guo, F., \& Huang, H. (2019). Research on echelon use of power battery. Chinese Journal of Power Sources, 43(4), 702-705. 